\title{
Mulheres que Matam: duas sentenças contrastantes - dois casos similares
}

\author{
Álvarez Santiago \\ Universidad Nacional Arturo Jauretche, Buenos Aires, Argentina \\ E-mail: alvaresantiago@hotmail.com

\section{Castelnuovo Biraben Natalia} \\ Universidad de Buenos Aires, Buenos Aires, Argentina \\ E-mail: naticastelnuovo@gmail.com
}




\section{Resumo}

Neste artigo propõe-se comparar dois casos jurídicos aparentemente semelhantes protagonizados por mulheres que assassinaram seus parceiros agressores. Porém, trata-se de casos que apresentam resultados jurídicos contrastantes. Pois enquanto num deles o tribunal condenou a mulher, no outro ela foi absolvida, alegando que o homicídio foi em "legítima defesa". Trata-se então de casos análogos e de sentenças contraditórias? Ou, pelo contrário, esses casos são muito dissimiles e não seriam então contraditórios na sentença? Sem desprezar o fato de que nenhum caso é igual a outro, encontra-se nas análises dos dois casos um conjunto de semelhanças evidentes. Refere-se especificamente aos casos de Graciela Aguirre e Valeria Pérez Aquino, acontecidos no ano de 2007. O primeiro foi no distrito de La Matanza, província de Buenos Aires, e o outro, na província de Chubut. Este estudo considera como fontes os meios de comunicação, especialmente os jornais, para analisar um dos espaços dentre os quais são construídas moralidades e valores que envolvem representações sobre as relações de gênero, a dualidade vítima/agência e a violência de gênero.

Palavras-chave: Moralidades. Violência de Gênero. Meios de Comunicação. Argentina.

\section{Abstract}

The purpose of this article is to compare two juridical cases that, at a first glimpse, seam to be similar. Both of them were homicides in which women kill their abusers. However, both cases have contrasting juridical results. Meanwhile in one of the cases the court condemned the killer, in the other she was considered not guilty asserting that the homicide was in "legitimate defence". Are this cases similar but with contradictory sentences? Or, on the contrary, are this affairs really different and thus there is no contradiction in the judgements? It is obvious that no case is equal to other but in the analysis of both we come across to a series of similarities. We specifically refer to the Graciela Aguirre and Valeria Pérez Aquino cases that happened during the course of 2007. The first took place in La Matanza, Buenos Aires province, the other in the Patagonic province of Chubut. This study takes into account and selects media sources, specially from newspapers, to analyse how moralities and values around gender relations, victim/agency and gender violence are constructed.

Keywords: Moralities. Gender Violence. Media, Argentina. 


\section{Introdução}

丩 $\begin{aligned} & \text { yriam Jimeno (2003, p. 55) considera que "[...] a ação violenta } \\ & \text { está impregnada de significados vindos da sociedade especí- }\end{aligned}$ fica em que ocorre". Nesse sentido, considera-se que analisar dois casos de crimes passionais na Argentina esclarecerá não somente as características particulares de cada um deles ou as condições jurídicas existentes no país, mas também a forma na qual a sociedade entende "as violências" exercidas contra a mulher e a representação dominante e midiática da violência de gênero. Entende-se que o significado desse tipo de violência depende da identidade das partes envolvidas e que, como aponta Engle, é necessária para compreender uma análise situada que reconheça "[...] os efeitos do contexto social mais amplo que o das performances de gênero" (Engle, 2009, p. 3). Assim, considera-se os tipos de vínculos existentes entre as pessoas, as condições sociais nas que se desenvolvem as ações violentas e, por último, os modos de intervenção dos esquemas cognitivos e emocionais aprendidos na vida social.

No presente trabalho propõe-se a análise de dois casos semelhantes com sentenças contrastantes: o de Graciela Aguirre e o de Patricia Aquino. Descreve-se as condições particulares de cada um dos casos para depois compará-los e refletir sobre os parâmetros desde os quais se constroem moralidades e valores que envolvem as representações sobre as relações de gênero, a dualidade vítima/agressor e a violência familiar. Será levado em consideração o modo em que os meios de comunicação, mais particularmente a imprensa, apresentaram os fatos.

O primeiro caso é protagonizado por Graciela Aguirre, uma mulher que foi acusada de ter cometido homicídio ao esfaquear o seu 
marido na frente dos seus filhos, provocando sua morte. Depois de estar detida durante seis meses no calabouço de uma delegacia e ter cumprido prisão domiciliar, o Tribunal a absolveu alegando sua legítima defesa ${ }^{1}$. No segundo caso, trata-se de Valeria Pérez Aquino, acusada de ter assassinado seu marido jogando nele água fervendo enquanto ele dormia. Os juízes condenaram-na a sete anos de prisão domiciliar por homicídio simples². Vale a pena apontar que o Código Penal está vigente em todo o espaço territorial. Porém para os delitos comuns ele é aplicado pelos juízes de cada Província, o que provoca frequentemente interpretações díspares. A pergunta é: quais foram as razões que levaram os distintos juízes a ditar sentenças tão diferentes? Como se vê, ambos os casos apresentam mulheres que tinham sido objeto de violência doméstica. Trata-se de critérios jurídicos utilizados para definir a culpabilidade e/ou a inocência das acusadas, ou se está na frente de critérios baseados em outras motivações? Serão analisadas as representações elaboradas pelos meios de comunicação, as sentenças e suas considerações.

\section{Os Casos Aguirre e Aquino}

Segundo as fontes jornalísticas ${ }^{3}$, unânimes na descrição dos fatos, estes aconteceram da seguinte forma:

Graciela Aguirre era objeto de frequentes expressões de violência por parte do seu marido. No dia dos fatos, Ricardo Oscar Ávila havia bebido aproximadamente uma garrafa de vodka no aniversário de uma amiga da sua filha, que era festejado na casa deles. O álcool levou Ávila a um estado de excitação e violência. Assim, ele começou a insultar e ameaçar de morte Graciela, sua companheira, e os seus filhos. Ávila tirou uma faca da cozinha e amedrontou as pessoas ali presentes. Devido ao seu estado de embriaguez, perdeu a faca. Esta passou às mãos de Graciela Aguirre que a lançou sobre Ávila de uma distância aproximada de três metros, cravando-o no pescoço e produzindo sua morte por dessangramento.

Segundo as fontes jornalísticas ${ }^{4}$, no segundo caso os acontecimentos se desenvolveram da seguinte forma: 
Os jornais retratam Valeria Pérez Aquino como una imigrante boliviana, analfabeta e falante de quechua, que sofria violência física e psicológica constante por parte do seu marido. Aparentemente ela não teria denunciado a Rocha Rocabado, seu esposo, por estas ações violentas, pois cada vez que ela se dispunha a fazer isso, ele a teria persuadido de que a polícia não a levaria a sério dada sua condição de boliviana e as suas dificuldades para se expressar em castelhano. Valeria deu sua versão dos fatos e relatou que no dia do crime, seu marido chegou bêbado à sua casa, agrediu-a física e verbalmente e lhe ordenou que preparasse comida quente. Ela respondeu que estava dando atenção para o seu filho deficiente, e ele respondeu que ela deveria seguir suas ordens. No momento de sofrer a agressão, Rocha encontrava-se recostado e descansando numa cama. Aquino verteu água fervendo sobre o rosto do seu parceiro, produzindo queimaduras em $63 \%$ do seu corpo.

Da análise da sentença de Graciela Aguirre resulta sumamente interessante o fato de que neste destaca-se o papel central do seu advogado, caracterizado pela sua "coragem e valentia" ao assumir a defesa além dos recorrentes obstáculos que se apresentam neste tipo de julgamentos, onde a "voragem" e "preconceitos de alguns operadores judiciais" poderiam, tal como se apresenta na sentença, ter interferido negativamente na resolução do caso. Outro aspecto que deve ser destacado é a escassa operatividade da Lei n. 12.569 de "Violência Familiar" e o "mal emprego" dos "mecanismos de contenção" pela própria Aguirre ou a "pouca atenção" recebida de parte de entidades estatais ou de bem público. Nesse sentido, chamam a atenção as contradições que emergem do descrito na sentença, pois, se por um lado esta reconhece a existência de representações preconceituosas por parte dos operadores judiciais, isto não significa/não é percebido como um impedimento/obstáculo na avaliação que é feita da operatividade da Lei, sendo que ela é aplicada por esses mesmos funcionários.

Da análise da sentença de Valeria Pérez Aquino5 ${ }^{5}$, é preciso destacar especialmente o fato de que, se encontrando o caso em estado de ditado de sentença, o Tribunal fez matéria de reflexão se devia ou não admitir a formulação de nulidade do procedimento pelas razões 
explicitadas pela Defesa Técnica da imputada. A nulidade concebe-se na base de não se ter designado para a imputada um tradutor da sua língua quechua, o que significou que ela não conseguiu se inteirar do processo nem no ocorrido nas audiências. Por outro lado, foi questionado se a imputada teria ou não agido sob o amparo da excludente de ilicitude de legítima defesa da sua pessoa. No pedido de nulidade da causa, foi dada preeminência ao fato de que a imputada tenha sido ou não "avaliada" adequadamente no "informe" elaborado pelos peritos em distintos saberes (principalmente o de médicos forenses, psicólogos e trabalhadores sociais). Percebe-se que se eram estes os profissionais responsáveis por encontrar "provas" para fundamentar a sentença e a avaliação a respeito de se a imputada teria ou não agido em "legítima defesa", é difícil explicar como realizaram a avaliação médica e da sua "pessoalidade" se tratando de uma pessoa monolíngue. Vale a pena destacar que isto não impediu que, no informe psicológico, Aquino fosse caracterizada como uma pessoa que “[...] apesar de morar na Argentina há aproximadamente 23 anos, exibe resistência a deixar de lado sua língua originária e adotar o castelhano, informa-se que somente agora começa a aprender $[\ldots]$ " e "[...] utiliza a linguagem gestual para ser compreendida". Também não se entende como podem ter concluído que a Sra. "[...] é produto de uma dinâmica familiar doentia, distorcida, de grande primitivismo dos seus membros $[\ldots]$ " e que "[...] apesar do seu baixo nível mental e cultural, compreende seu ato e se mostra arrependida, nisso tem muito de confusão, ambivalência, necessidade imediata de sobrevivência". Os ditos dos informes e sentenças dizem sobre as representações referidas à família e à mulher e, fundamentalmente, com respeito a como operam uma série de preconceitos por parte dos peritos ao avaliar se a pessoa imputada corresponde ou não ao estereótipo da vítima de violência familiar e/ ou de gênero.

\section{Algumas Diferenças e Semelhanças}

Em primeiro lugar, observa-se que Graciela Aguirre havia denunciado que sofria violência em diversas ocasiões nas delegacias do seu bairro. Pelo contrário, talvez pela sua condição de imigrante, 
falante de quechua e analfabeta, Valeria Pérez Aquino nunca tinha apresentado denúncias. Porém, os fatores fundamentais que influem decisivamente na categorização jurídica de ambos os casos são outros. Trata se principalmente dos limites clássicos da legítima defesa e as circunstâncias jurídicas nas quais um crime é considerado "passional", o qual segundo Jimeno (2004) estrutura-se sobre três pressupostos: a violência é representada como uma ação "louca" ou de "loucura emocional" e a emoção tem um papel diferencial segundo o gênero; considera-se que a violência explode e um sentimentalismo de amor cobre a relação com a morte. No caso Aguirre, observa-se que ela é retratada tomando o instrumento do crime do seu marido, que minutos antes havia lhe agredido e ameaçado, tendo também ameaçado seus filhos. Isso nos conduz a interpretar que a sua reação não pode ser considerada como premeditada. Aparentemente, depara-se um caso típico de legítima defesa. É importante destacar que, para Stephanie Brommer (1997), a legítima defesa e o estado de emoção violenta são instituições que levam em consideração as particulares características da psique masculina. Em outras palavras, é o homem adulto heterossexual quem reage espontânea e apaixonadamente. Brommer (1997) explora o que ocorre nos juízos quando se apresenta como legítima defesa. Segundo a autora, em estudos realizados com mulheres que assassinaram seus ofensores, observou-se que somente entre um vinte e vinte cinco por cento das mulheres julgadas que alegaram legítima defesa foram absolvidas, enquanto os cinquenta e setenta e cinco por cento restantes receberam sentenças de prisão por seis meses ou mais (1997). Situação essa que se relaciona com a definição clássica da legítima defesa: "[...] o modelo masculino no clima da briga, [...]" (Brommer, 1997, p. 8). Na maioria dos casos de defesa pessoal se apela ao comportamento masculino standard que justifica o assassinato, seja no caso de um assalto a mão armada, se não existe nenhuma possibilidade de fugir ou se afastar ou se a força utilizada em legítima defesa não é excessiva em relação à necessária para a prevenção do ataque. Diante disso, as diferenças que emergem da desigualdade de gênero continuam não sendo levadas em consideração. O critério tradicional utilizado na defesa própria ignorava as diferenças de tamanho e forca física entre homens e mulheres. Além disso, como aponta Brommer 
(1997, p. 8), este critério ignora "[...] a dependência econômica que prende muitas mulheres dentro destas relações abusivas".

Seguindo Brommer (1997; Harvey y Gow, 1994), no caso das mulheres que assassinam seus abusadores, a agência delas não se desenvolve desta maneira clássica. A mulher que sofre uma violência cotidiana reage dificilmente em concordância com estes parâmetros. Dado que usualmente ela é fisicamente mais fraca que o homem abusador, ela aguarda uma possibilidade de estar em situação de vantagem. É por isso que com frequência as mulheres que matam os seus abusadores, o fazem enquanto eles dormem, ou utilizando em alguns casos veneno, ou pedindo alguém para matá-los. Invocar a retórica da frialdade e o cálculo feminino é o contrário da retórica de sentimento, o que exibe seu tom de gênero. Assim para as mulheres rotuladas como "calculistas" fica mais difícil a sua defesa pela via da exaltação emocional. As representações mais frequentes da mulher a colocam como fraca, sensível, delicada, e de jeito nenhum agressiva ou violenta. Então, como mantém Elizabeth Badinter (1993), nos chamados crimes passionais quando a mulher emprega a violência, ela não somente viola a proibição de matar, mas também transgride o que se supõe ser a sua própria condição feminina. É também por isso que muitas mulheres em caso de homicídios simples utilizam a justificativa de demência como estratégia de defesa. Essa decisão dos advogados baseia-se no fato de que a demência, diferentemente da legítima defesa, se sustenta na crença social de que a violência e a agressão são antinaturais na mulher (Brommer, 1997).

Retomando os dois casos apresentados, perguntamo-nos por que as duas agências femininas como capacidade de empreender uma ação (Scott, 1985), foram julgadas de jeito diferente, uma assumindo o perfil da vítima e a outra ficando por fora desta categoria e assumindo o papel de verdugo (Brunatti, 2003)? E também, como são considerados esses crimes passionais? Ao respeito, Myriam Jimeno (2004, p. 56) nos diz que:

[...] fora do mundo das relações sociais, o sentimentalismo do amor e a concepção moderna da pessoa, contribuem a uma apreciação social benevolente destes homicídios. Além disso, a prevalência masculina a cometer este 
homicídio revela o papel das hierarquias de gênero e o valor da força na construção identitária de masculinidade e feminilidade em nossas sociedades.

Isso tem levado à organização mundial da saúde (OMS) a considerar a "síndrome da mulher agredida". Esta síndrome é caracterizado como a máxima inabilidade que possui a vítima de reagir frente à violência do seu ofensor, a incapacidade psicológica de fugir quando está sendo atacada ou de abandonar ao agressor. Brommer (1997, p. 5-6) descreve a síndrome assim:

[...] aparece quando a violência foi utilizada como meio de exercer o controle e o poder sobre a conduta de uma mulher sem levar em consideração seus direitos e com frequência conduz a traumas [...]. Os sintomas incluem a fraqueza aprendida, a depressão, os flashbacks, os problemas de sono e de alimentação, os sobressaltos exagerados e a vigilância frente a um sinal de perigo. $\mathrm{O}$ isolamento e a incapacidade de saber em quem confiar também restringem as opções percebidas pelas mulheres. A debilidade apreendida forma parte da síndrome e ocasiona a perda da crença em que uma classe de resposta possa conduzir a um bom resultado. Isto não significa que a mulher seja incompetente, débil ou passiva, mas que ela estreita seu leque de respostas em relação com aquelas que têm mais possibilidades de gerar respostas bem-sucedidas.

Os psicólogos forenses e/ou advogados utilizam a síndrome que considera as características particulares das mulheres que sofrem violência por parte dos seus abusadores como meio para demonstrar que se tratou de um ato de legítima defesa. O argumento dos advogados baseia-se na interpretação de que

[...] uma mulher maltratada pode cometer o que aparentemente pareceria ser um crime premeditado como, por exemplo, matar o seu marido quando dorme, enquanto o que ocorreu na realidade é que ela agiu se sustentando na crença de que não existia escapatória e que ele retornaria para machucá-la ou matá-la se ela não o fizesse antes, ou que agiu em resposta a uma ameaça da qual não poderia escapar de outro modo. (Brommer, 1997, p. 6) 
Os psicólogos que tratam esse tipo de mulheres que padecem desta síndrome, as descrevem como pessoas que se sentem presas, sob um perigo constante, impossibilitadas de abandonar seu parceiro, correr para longe, fugir, chamar a polícia, obter um divórcio ou pedir algum tipo de ajuda. Com frequência, estas pessoas acreditam que mesmo realizando estas ações não conseguirão deter seu agressor. Mas, se é certo que para os psicólogos, médicos e trabalhadores sociais a evidência da síndrome é chave na defesa da mulher, a percepção elaborada pelos juízes e advogados é outra. Os últimos são céticos no seu uso quando se trata de um assassinato. Em outras palavras, se bem a síndrome da mulher golpeada é reconhecido pelo corpo médico, desde o âmbito legal existe uma maior resistência a aceitar a síndrome, e uma tendência a ignorar a condição psicológica da mulher. Segundo Brommer (1997), todas as cortes judiciais nos Estados Unidos admitem a apresentação de algum tipo de evidência da síndrome, mas apenas 12 estados entre os 49 promulgaram decretos que admitem a presença de evidência da síndrome nas cortes.

No caso de Valeria Aquino, os meios de comunicação difundem a imagem de um homem indefeso no momento do crime, e ela é retratada quase à espera das circunstâncias ideais (seu esposo no sofá) para lhe jogar água fervendo. Seguramente isto também foi assim interpretado pelos juízes, como um caso que não se enquadrava na tipologia clássica da legítima defesa. Um caso análogo é analisado por Myriam Jimeno. Trata-se da história de Marli, uma mulher brasileira que mandou matar seu marido e que, não admitindo plenamente a sua responsabilidade nem assumindo que se tratava de um homicídio mediante pagamento, lhe foi negada a possibilidade de argumentar que o seu estado emocional estava alterado, o que teria lhe permitido mitigar a condenação. Pelo contrário, em outros relatos analisados pela mesma autora, abundavam as expressões tais como "foi um acesso de ira", "a emoção me tomou e perdi a cabeça", "foi um momento de exaltação emocional", "não sei o que me passou, ceguei-me de ciúmes" (Jimeno, 2004, p. 60). Esses argumentos são fundamentais para os defensores que com grande frequência alegam tanto uma loucura momentânea, um amor doentio como também uma doença de patologia ligada aos ciúmes. Retomando a representação do ato de Aquino 
é possível observar como, na análise judicial, esta é isolada de toda uma série de circunstâncias prévias - a violência doméstica constante e repetida da qual era objeto, seu analfabetismo, seu desconhecimento sobre seus direitos, sua condição de imigrante e o isolamento em que vivia, etc. Porém, o fato de não ter denunciado foi o argumento privilegiado no momento de avaliar seu ato, que foi classificado como um mero homicídio simples. Parte do argumento baseou-se em que seu esposo estivesse inerme e sem possibilidades de defesa. Segundo Página 12, La Nación y La Patagonia, ele estava numa posição "deitada" e, portanto, sem poder reagir.

Outra foi a interpretação proposta para o caso de Graciela Aguirre. A leitura dos acontecimentos centrou-se no fato de que ela assassinou seu parceiro com a faca que ele havia utilizado para tentar agredi-la. Pareceria se tratar de um homicídio não premeditado. Como expressou a própria Aguirre: "nunca pensei que ia matá-lo". "lhe atirei [a faca] às cegas", indicou. E agregou: "Sem intenção de matá-lo". Explicou que sentia "muito medo" de que seu esposo a assassinasse e também a seus filhos, mas afirmou que "jamais" pensou em assassiná-lo e especificou que "foi um acidente" (La Nación, 16/02/09).

Assim, enquanto Aguirre aparece como uma vítima porque sua atuação está limitada por uma situação de fatalidade no meio de um ataque do seu marido, Aquino, pelo contrário, é apresentada como calculista e com as características de agência consideradas negativas para uma mulher. Ela é representada reiteradas vezes se aproveitando, agindo premeditadamente e com aleivosia, frente ao retrato quase dócil de um homem, seu companheiro, que numa situação de repouso e quase extrema indefensabilidade recebeu a água fervendo que ela verteu sobre ele. Doravante, não podem ser consideradas as condições particulares da sua ação e o contexto no que se desenvolveram porque significaria levar em conta uma representação diferente da mulher e das suas possibilidades de agência.

\section{Vitimização ou Agência?}

Connel (1997, p. 115-116) critica a dicotomia "vítima-agência", pois considera que "A opressão da mulher é frequentemente anali- 
sada em termos do conceito de vitimização". Segundo essa autora, trata-se de uma categoria com certa funcionalidade. Pois, aquelas mulheres que conseguem se apresentar em termos das ideias aceitas e generalizadas sobre o que é entendido como uma vítima inocente obterão resultados legais favoráveis (Connel, 1997; Brunatti, 2003). Olga Brunatti (2003) descreve como em um centro de assistência à vítima, as próprias psicólogas e trabalhadoras sociais falam das mulheres "vulneráveis" como aquelas que se amoldam a um estereótipo de mulher passiva e discreta frente às "fabuladoras", geralmente mulheres ativas, que se apresentam ao centro de assistência vestidas de uma maneira descrita como "provocativa". A rejeição a constituir este modelo de autorrepresentação levanta interessantes perguntas sobre a habilidade do sistema legal de ditar justiça para a mulher que não cumpre um modelo particular de vitimização. Como sustenta Haraway (1991, p. 155),

Não tem nada no ser "feminino" que naturalmente se prenda à mulher. Nem sequer existe tal estado de "ser" feminino; esta é em si uma categoria altamente complexa construída em discursos científicos já refutados sobre sexualidade e outras práticas sociais. A consciência de gênero, raça ou classe é um sucesso forjado em nós pela terrível experiência histórica, as contraditórias realidades sociais do patriarcado, o colonialismo e o capitalismo.

Connel (1997, p. 118), por sua vez, define a agência nestes contextos como "[...] o exercício de qualquer tipo de medida de resistência ou autodeterminação utilizada por uma mulher abusada para recuperar o controle da sua vida e sua tentativa por frear os abusos que experimenta". Daí que a agência, como já se apontou, seja em muitas ocasióes percebida negativamente, exceto naqueles casos que esta aparece associada ao abandono da situação de violência. Como argumenta Connel (1997, p. 119), “A ênfase na saída pode estar relacionada com focalizar no dano que as mulheres vivem e no fato de ver o dano como o que define sua relação, sem considerar o contexto dentro do qual o dano ocorre". Isso não significa negar que a estratégia mais apropriada possa ser deixada à própria pessoa (como acontece com frequência), mas levar em consideração que a justiça estigmatiza aquelas mulhe- 
res que não abandonam nem denunciam seus parceiros agressores. Tal perspectiva poderia também confundir uma mulher que escolhe conscientemente permanecer dentro de uma relação abusiva por várias razões que incluem o amor, mas que está muito comprometida em tentar fazer com que a relação funcione e em buscar ajuda para deter os abusos, sem por isso minimizar o dano psicológico e emocional que causa a ela e seus filhos. Porém, pareceria que as diferentes ações das mulheres de autoafirmação e tentativas de deter e mudar o patrão de abuso na relação "[...] estão subsumidas sob a armadilha retórica do ficar ou ir embora". (Connel, 1997, p. 119)

Segundo Brommer (1997), a unidade da lei se manifesta na maneira em que a linguagem é usada nas práticas representacionais, no silenciamento das diferentes perspectivas, na negação da experiência e no esforço de transformar o conhecimento em algo objetivo. Essas são para Brommer manifestações de violência que cercam o tratamento legal das mulheres que matam seus ofensores.

\section{Os Meios Gráficos}

A imprensa incorre numa polarização na qual prevalece a dicotomia vítima/agência. As duas famílias analisadas são percebidas e caracterizadas descritivamente de modo diferente, se constituindo assim uma valorização moral em torno das ações empreendidas por estas duas mulheres.

Levando em consideração as características sociais de ambos os casos, há pouca informação sobre o lar dos Ávila Aguirre: não aparecem nos jornais nem nas sentenças dados das suas ocupações. Sabe-se sim que moravam no distrito de La Matanza, em um apartamento de três ambientes e que tinham dois filhos. Possivelmente, pelas características da descrição, tratar-se-ia de um apartamento de classe média. Em 16 de fevereiro de 2009, o Jornal La Nación reproduzia a posição do promotor fiscal ${ }^{6}$ Ariel Panzoni que, ao relatar os danos físicos e verbais que sofriam, considerava que Aguirre tinha agido em legítima defesa, já que "tanto ela como sua filha me pareceram de uma total verossimilitude e total sinceridade". 
A acusada assegurou que na sua casa existiam situações de "violência e agressões", que Avila "bateu muito nela quando estava grávida" e que os ataques eram "cotidianos" (La Nación, 16/02/09). "Eu fui embora da minha casa, mas ele me seguia, me ameaçava por telefone, ameaçava minha família, dizia que ia me queimar, que voltasse com ele pois iria mudar, que não ia mais me bater, que se eu não voltasse ia incendiar a casa da minha mãe ou que ia me matar", assegurou. Aguirre detalhou as circunstâncias que a levaram a adotar esse gesto que precisou realizar para "defender a sua filha", que também estava sendo atacada pelo pai (Jornal El Argentino, 16/02/09). Graciela Aguirre comenta recorrentemente que teria assassinado seu esposo para "defender" seus filhos. O que leva seus defensores a solicitar que o caso seja julgado como um fato de "homicídio em legítima defesa própria e dos seus filhos" (Jornal El Argentino, 16/02/09). "A única coisa que eu sei é que eu o fiz para defender meus filhos. Graças a Deus o perito interpretou assim", concluiu a mulher. "Eu o matei por causa dos meus filhos", disse Graciela (Derf. Agencia Federal de Noticias, 16/02/09). Durante uma entrevista emitida pela Rádio Continental, expressa seu arrependimento pelo acontecido, mas explicou que "qualquer mãe teria agido assim para defender seus filhos" (17/02/09).

O caso Aguirre adquire ressonância política e se converte quase em um "leading case" para o ministro de Desenvolvimento Social da Província, Daniel Arroyo, que o considerou como "um chamado de atenção" e enfatizou a necessidade de visibilizar "uma problemática que afeta a muitas mulheres e crianças" (La Plata-Buenos Aires, 16/02/09, Agencia NOVA). A legítima defesa de Aguirre é reconhecida desde o início, baseando-se no contexto cotidiano de violência doméstica no qual vivia?

A descrição da família Aquino é muito mais minuciosa. Ela é apresentada como uma imigrante boliviana, analfabeta, falante de quechua que aparentemente identificava-se como dona de casa devido ao cuidado do seu filho deficiente. Seu marido era pedreiro, formando parte dos setores mais baixos da classe trabalhista. Moravam na cidade de Puerto Madryn, Chubut. Todos os jornais mencionam o informe da psicóloga forense que descreve Aquino como uma mulher de: “[...] 
pessoalidade primitiva e impulsiva com um nível intelectual de grande precariedade e caráter que oscila entre a submissão e a introversão, porém apresente em parte, atitudes impulsivas e de extroversão" (Clarín, Página 12, Diario 26 Noticias). Sua vida familiar é definida como "patológica" com um tratamento muito violento e "animalesco" por parte do marido. Daí que a mulher desenvolvesse um sentimento de "hostilidade" que cresceu pelos maus-tratos. O adjetivo "animalesco" é também utilizado pelo informe forense para caracterizar Aquino e não seu marido. Assim os jornais adotam este adjetivo para se referir as suas características particulares. O informe agrega que Valeria possuía o medo que seu esposo agredisse seu filho deficiente. Nas suas declarações, ela diz que o motivo pelo qual decidiu jogar água fervendo foi que ele teria dito que na polícia ninguém iria acreditar nela porque era a própria "um animal". Segundo a sentença, Aquino deve cumprir oito anos de prisão domiciliar.

Outra diferença entre ambos os casos é que no primeiro existiam traços demonstrativos (ou evidências de violência) de violência: o homem bate no filho e joga um copo de vidro. Entretanto, no caso Aquino, destaca-se a ausência de evidências materiais que atestem violência ou briga entre os parceiros, a fim do estabelecimento de uma "legítima defesa".

No informe do Ministério Público Fiscal de Chubut, encontrou-se o testemunho elaborado pela psicóloga forense que realizou diversas entrevistas a Pérez Aquino e destacou "[...] sua pessoalidade primitiva e as humilhações às quais era submetida por parte da vítima" (13/02/2009). Ela relatou que essa noite seu marido chegou bêbado, a agrediu física e verbalmente e lhe ordenou que preparasse comida quente. Que perante as agressões pensou em ir até a polícia para denunciar as judiações das quais era vítima, mas seu marido lhe repreendeu dizendo que ninguém acreditaria nela porque ela "era um animal" (Ministério Público Fiscal de Chubut, 13/02/2009). A psicóloga destacou também que o caráter de Aquino "oscila entre a submissão e a introversão, porém apresente em parte atitudes impulsivas e de extroversão" (idem). Acrescentou ainda, que conta com "um nível intelectual de grande precariedade" (Diário 26 Noticias). 
Aquino morava há trinta e cinco anos na Argentina. A relação de vinte anos de violência com seu cônjuge não foi considerada pelo tribunal, levando em conta a falta de denúncias.

Segundo o testemunho de uma vizinha (Página 12): "Ela tem vivido violência toda a sua vida, todo esse tormento a gente o conhecia no bairro. Quase sempre tinha estado sem sair de casa, como se fosse uma vergonha o filho deficiente. Ele a tratava muito mal, a ultrajava. Na Bolívia, pelo machismo ensinam as mulheres a obedecer, a perdoar o marido. Ele lhe dizia que não iam acreditar nela se fosse a polícia, que era uma ovelha, que não sabia falar, que nem era boa para lhe dar filhos sadios. Viveu anos e anos de maltrato e violência" (27/02/09).

O advogado defensor de Pérez Aquino, Ricardo Antonio Sartor disse a Página 12 que apelará da sentença. "Ela não quis matar, não teve a intenção, só quis afastá-lo e tirá-lo de cima". O informe da psicóloga forense, Elsa Sánchez, mostra que a mulher "[...] tem sofrido situações diárias de grave maltrato físico e psicológico" (Página 12).

No caso de Aguirre, os filhos participam do fato tanto como vítimas das ameaças e insultos por parte do seu pai, como testemunhas da certeira facada da mãe e participam da fuga correndo do lar em procura de ajuda. Os filhos testificam que sua mãe sofria violência e que o ato foi em legítima defesa. Os filhos são apresentados positivamente dentro de um lar que não é catalogado em momento nenhum como patológico ou disfuncional. Nada disso ocorre no caso de Aquino, que mesmo tendo tido outros filhos maiores com seu parceiro, no momento do crime está acompanhada só pelo filho deficiente. De alguma maneira, nos informes dos peritos é possível observar uma estigmatização da família definida como patológica e dando a parecer que a deficiência do filho impregna ou contamina a análise das faculdades mentais dela. O perito forense assinalou que ela tinha "medo" que seu esposo agredisse seu filho deficiente. "Tanto tem sido golpeada que ainda tem rastros de feridas nas suas pernas, pelos chutes que recebia do seu esposo" (Página 12). Apesar de fazer trinta e cinco anos que Aquino morava na Argentina, sua "bolivianidade" é destacada até formar parte do núcleo explicativo de sua conduta. 


\section{Reflexões Finais}

Os casos de Aguirre e Aquino que num olhar superficial aparecem como similares e coincidentes, foram indubitavelmente percebidos pela imprensa e as autoridades judiciárias como claramente contrastantes e diferentes. Esses contrastes não se baseiam somente na aplicação da lei, particularmente nas figuras da emoção violenta e da legítima defesa. Além da letra da lei existe una concepção valorativa das ações das mulheres. Pois quando elas não cumprem com o modelo de representação feminino hegemônico, não podem ser percebidas como vítimas, portanto, o sistema legal dificilmente dita uma sentença ao seu favor. No caso Aquino, além das valorações prévias, existem preconceitos do tipo étnico e de classe relacionados com a pobreza e o caráter de imigrante boliviano. A família chega a ser associada a uma "animalidade". Paradoxalmente esta condição não age como atenuante, mas justifica a condenação. Os contrastes entre os dois casos permitem-nos afirmar que não são somente as reformas legais que modificam as sentenças, mas também as representações que operam nos distintos âmbitos e que acabam influindo para produzir a sentença judicial.

As sentenças estudadas podem ser pensadas na ótica de outro caso que também coloca em cena a diversidade de olhares existentes e particularmente as representações preconceituosas baseadas nas relações de gênero desiguais e em um único modelo de família que modelam as práticas dos operadores judiciais quando abordam este tipo de problemática. Refere-se à sentença de Carátula ${ }^{8}$ Leiva, María Cecilia, emitido pela Corte Suprema de Justiça da Nação Argentina e especialmente ao voto realizado pelas doutoras Elena Highton de Nolasco e Carmen Argibay. Dessa sentença entende-se que mesmo existindo um reconhecimento de um corpo de normas que se pronunciam contra toda forma de violência contra a mulher, isso não significa aceitar seu direito a uma "legítima defesa", pois, observa-se que argumentos tais, por exemplo, a imputada do caso "permanecia no domicílio onde morava com o assassinado" de forma "voluntária", são utilizados para argumentar que teria se "submetido livremente a uma hipotética agressão ilegítima". A importância desse caso em relação aos anteriormente analisados surge então quando se observa 
como o avanço e o reconhecimento das disposições de convenções internacionais e normas nacionais sobre a matéria não significam que as representações ideologizadas das mulheres que sofrem violência por parte dos operadores judiciais não tenham um lugar de peso no momento de decidir quem atuou em legítima defesa. Como se vê, seu saber pericial junto ao de outros profissionais tem um papel fundamental na avaliação que estabelece os parâmetros que dizem se o "perfil" da imputada corresponde ou não com a sua imagem da vítima desejada.

\section{Notas}

1 Aguirre, Graciela Haydé s/Homicidio simple. Tribunal Criminal n. 4 del Departamento Judicial La Matanza, causa n. 3.950, 16 de fevereiro de 2009.

2 A Lei n. 11.340/2006 "Maria da Penha" do estado brasileiro é especificamente dirigida à violência exercida contra a mulher. Somente o 11 dezembro de 2012 é sancionada na Argentina a Lei n. 26.721 que possui algumas semelhanças coma a brasileira e que incorpora algumas de suas providências. A sanção desta lei trouxe novas modificações no Artigo 80 do Código Penal Argentino. Estas consistem na inclusão de novas figuras agravadas de homicídio, se impondo uma reclusão ou prisão perpétua a quem matar sem se limitar ao homicídio do cônjuge. Estende-se a sanção tanto ao ex-cônjuge ou a pessoa com quem mantém ou tenha mantido relação de casal mediante ou não convívio, sem importar a antiguidade ou a existência de outro vínculo paralelo (Inciso I). A sanção se aplicará em todos os casos cuja motivação tenha sido "Por prazer, cobiça, ódio racial, religioso, de gênero ou a orientação sexual, identidade de gênero ou sua expressão (inciso 4). Também são incorporados os incisos 11 e 12 do Artigo 80 do Código Penal que referem especialmente à violência contra a mulher, estabelecendo a reclusão ou prisão perpétua a quem matar uma "mulher quando o fato seja perpetrado por um homem e mediar violência de gênero". E a quem o faça "com o propósito de causar sofrimento a uma pessoa com quem se mantém ou tenha mantido uma relação nos termos do inciso 1" (nosso destaque). No caso em que o verdugo "[...] já tenha realizado fatos de violência contra a mulher vítima". O cambio normativo não permite que o juiz encontre circunstâncias extraordinárias de atenuante.

3 No caso Aguirre utilizou-se as seguintes fontes: Página 12; Clarín; Crítica de los Argentinos; Artemisia; Agencia Nova; Radio Continental; Der. Agencia Federal de Noticias; El Argentino; La Nación. Alguns jornais são locais e outros nacionais. Todos tem um perfil democrático com nuances à direita e à esquerda.

4 As fontes utilizadas são página 12; La Nación; Clarín; La prensa boliviana; boletín Patagonia; El territorio; documentos del Ministerio Público Fiscal de Chubut; 26noticias.com.

5 Aquino recebeu uma condenação a prisão por oito anos por homicídio simples, sendo esta revocada no 26/02/09. A capa da causa é "Rocha Rocabado, Julio s./ Homicidio r/víctima" (CJ n. 1001/08 - LF n. 7. 462/08), com sentença no dia 24 de novembro de 2010 da Cámara en lo Penal, Circunscripción Judicial de Puerto Madryn, província de Chubut. 
6 Referimos ao fiscal do juízo, funcionário público integrante do Ministério Público que dirige a pesquisa criminal e a ação penal pública.

7 "Foi porque entendeu que Aguirre agiu em legítima defesa, como estabelece o artigo 34 do Código Penal, que exime a pessoa envolvida num fato violento quando age em defensa própria ou de terceiros" (Crítica de los Argentinos, 17/02/09).

8 A "carátula judicial" é um termo usado nos antigos sistemas processais (inquisitivos e estruturais), que hoje não mais existe, mas é usado pelos jornalistas na Argentina. Existem casos que levam um número e ano de registro e uma designação onde aparece o nome do acusado, o delito imputado, e uma sucessão de atos processais relativos a este registro. Os termos corretos para referir-se à compilação de provas e atos processais relacionados a um caso são Expediente Judicial ou Legajo judicial.

\section{Referências}

AGUIRRE, Graciela Haydé. s./Homicidio simple. Tribunal Criminal n. 4 del Departamento Judicial La Matanza, causa n. 3.950, 16 de fevereiro de 2009.

ÁLVAREZ, Santiago. El gallinazo en la escuela. Em Rifiotis y Castelnuovo (Comp.). Antropología, violencia y justicia: repensando matrices de la sociabilidad contemporánea en el campo del género y de la familia. Buenos Aires: Editorial Lumen, 2009.

ÁLVAREZ, Santiago. La distancia en el discurso profesional de la justicia argentina: la representación de la criminalidad en la justicia penal ante la 'nueva ola' de violencia delictiva". Em Sandra Gayol y Gabriel Kessler (Comp.), Violencias, delitos y justicias en la Argentina. Buenos Aires: Manantial, Universidad de General Sarmiento, 2002.

BADINTER, Elizabeth. XY La identidad masculina. Colombia: Norma, 1993.

BROMMER, Stephanie. The legal liminality of battered women who kill their abusers. Polar, Political and Legal Anthropology Rewiew, American Anthropological Association, Arlington, v. 20, n. 2, p. 16-33, 1997.

BRUNATTI, Olga. Construyendo la víctima adecuada. CEDEAD Antropología y Derecho, Posadas, año 1, n. 2, 2003.

CASTELNUOVO, Natalia. Frente al límite: las trayectorias de mujeres que sufrieron violencia. Buenos Aires: Antropofagia, 2006.

CONNELL, Patricia. Understanding Victimization and Agency: considerations of race, Class and Gender". Polar, Political and Legal Anthropology Rewiew, American Anthropological Association, Arlington, v. 20, n. 2, p. 115-143, 1997. 
HARAWAY, Donna. Simians, Cyborgs and Women: the reinvention of nature. London: Free Association Books, 1991.

HARVEY, Penelope; GOW, Peter. Sex and Violence (Ed.). London: Routledge, 1994.

LEIVA, María Cecilia. s./Homicidio simple. Fallo de la Corte Suprema de Justicia de la Nación. n. 334, Buenos Aires, l de noviembre de 2011.

MYRIAM, Jimeno. Narrando la violencia. Relatos de pasión y muerte. Anuario de Estudios en Antropología Social, Buenos Aires: Centro de Antropología Social-IDES, Antropofagia, 2004.

RIFIOTIS, Theophilos; CASTELNUOVO, Natalia. "La "violencia" como punto de partida. In: RIFIOTIS, Theophilos; CASTELNUOVO, Natalia.

(Comp.). Antropología, violencia y justicia: repensando matrices de la sociabilidad contemporánea en el campo del género y de la familia. Buenos Aires: Editorial Lumen, 2009. (no prelo)

RIFIOTIS, Theophilos; CASTELNUOVO, Natalia. Introducción: razones para un libro. In: RIFIOTIS, Theophilos; CASTELNUOVO, Natalia.

(Comp.). Antropología, violencia y justicia: repensando matrices de la sociabilidad contemporánea en el campo del género y de la familia. Buenos Aires: Editorial Lumen, 2009. (no prelo)

ROCHA, Rocabado Julio. s./Homicidio r/víctima" (CJ n. 1001/08 - LF n. 7. 462/08), con sentencia del día 24 de noviembre de 2010 de la Cámara en los Penal, Circunscripción Judicial de Puerto Madryn, provincia de Chubut. Disponível em: < http://www.maraustralis.com/261110valsentencia.html>. Acesso em: 29 mar. 2014.

SALLY, Merry Engle. Gender violence: a cultural perspective. Singapore: Wiley-Blackwell, 2009.

SCOTT, James. Los dominados y el arte de la resistencia. Discursos ocultos. México, Ed. Era, 2004.

\section{Fuentes Periodísticas}

Agencia Nova, Agencia de Noticias de la Provincia de Buenos Aires, La Plata, 17/02/2009: < http://www.agencianova.com/nota. asp?n=2009_2_178id=6948\&id_tiponota $=10>$

Artemisa, Portal de noticias jurídicas, Buenos Aires, 20/02/2009: < http:// www.artemisanoticias.com.ar/site/notas.asp?id $=268$ idnota $=6422>$

Artemisa, Portal de noticias jurídicas, Buenos Aires, 26/02/2009: < http:// www.artemisanoticias.com.ar/site/notas.asp?id $=268$ idnota $=6424>$ 
Boletín Patagonia (Jornal on-line) Comodoro Rivadavia, 26/02/2009: <http://www.boletinpatagonia.com/content/view/2610/26/>

DERF, Agencia Federal de Noticias, Buenos Aires 16/02/ 2009: < http:// www.derf.com.ar/despachos.asp?cod_des $=2482398 I D \_S e c c i o n=33>$

Diario El Argentino (Jornal), on line, Buenos Aires 16/02/2009: < http:// www.elargentino.com/nota-28855-Graciela-Aguirre-Mato-a-su-marido-yfue-absuelta.html>

Diario Clarín (Jornal), Buenos Aires, 16/02/2009: < http://www.clarin.com/ diario/2009/02/16/policiales/g-01859657.htm>

Diario Clarín (Jornal), Buenos Aires, 17/02/2009: < http://www.clarin.com/ diario/2009/02/17/policiales/g-01860409.htm>

Diario Crítica de los argentinos (Jornal), Buenos Aires, 17/02/2009:

$<$ http://criticadigital.com/index.php?secc $=$ nota\&nid $=18876>$

Diario El Territorio (Jornal) on-line, Trelew, 28/02/2009: <http://

elterritorio.com.ar/nota.aspx?c $=2879862410495507>$

Diario La Nación (Jornal), Buenos Aires, 17/02/2009: <http://www. lanacion.com.ar/nota.asp?nota_id $=1100353>$

Diario La Nación, Buenos Aires, 16/02/2009: < http://www.lanacion.com.ar/ nota.asp?nota_id $=1100411>$

Diario La Prensa (Jornal), Buenos Aires, 28/02/ 2009: <http://www. laprensa.com.bo/noticias/28-02-09/28_02_09_socd 1.php >

Diario Página 12 (Jornal), Buenos Aires, 17/02/ 2009: <http://www. pagina 12.com.ar/diario/elpais/subnotas/120095-38275-2009-02-17.html>

Diario Página 12 (Jornal), Buenos Aires, 18/02/2009: < http://www. paginal2.com.ar/diario/sociedad/3-120619-2009-02-27.html $>$

Diario Página 12 (Jornal), Buenos Aires, 27/02/ 2009: <http://www. pagina 12.com.ar/diario/sociedad/3-120141-2009-02-18.html>

Diario Perfil (Jornal), Buenos Aires, 27/02/2009: < http://www.diarioperfil. com.ar/edimp/034l/articulo.php?art=12913\&ed=0341 \# sigue $>$

Diario 26 (Jornal on line), Buenos Aires, 27/02/2009: < http:// www.26noticias.com.ar/hallan-culpable-a-mulher-que-mato-a-su-maridotras-arrojarle-agua-hirviendo-83782.html>

DSD, Diario sobre Diarios, Portal Online, Buenos Aires, 17/02/2009:

<http://www.diariosobrediarios.com.ar/eldsd/diario/2009/febrero/diario-17febrero-2009.htm>

Ministerio Público Fiscal Provincia de Chubut, Rawson, 13/02/2009:

<http://www.mpfchubut.gov.ar/blog/?p=1106> 
Álvarez Santiago e Castelnuovo Biraben Natalia

Ministerio Público Fiscal Provincia de Chubut, Rawson, 13/02/2009:

$<$ http://www.mpfchubut.gov.ar/blog/?p=1024>

Radio Continental, Buenos Aires, 17 /02/ 2009: <http://www.continental. com.ar/nota.aspx?id=764445>

Recebido em 11/11/14

Aceito em 07/06/2015 